\title{
Diagnosis of patients with Prader-Willi and Angelman Syndromes: the importance of an overall investigation
}

\author{
Monica Castro Varela, Cintia Fridman and Célia Priszkulnik Koiffmann \\ Centro de Estudos do Genoma Humano, Departamento de Biologia, Instituto de Biociências, \\ Universidade de São Paulo, São Paulo, SP, Brazil.
}

\begin{abstract}
Seventy-two patients with clinical diagnoses of Prader-Willi (PWS; $n=28$ patients) or Angelman syndromes (AS; $\mathrm{n}=44$ patients) were submitted to chromosome analysis, SNRPN-SNURF exon 1 methylation assay, and microsatellite genotyping. Analysis of the methylation pattern confirmed the PWS diagnosis in 18 out of 28 patients and the AS diagnosis in 20 out of 44 patients. FISH and microsatellite analysis detected a deletion in 30 patients (14 PWS and 16 AS). Eight patients had normal FISH results (4 PWS and 4 AS); microsatellite markers showed that these patients had a uniparental disomy (UPD). Based on this study, we propose a strategy for the routine diagnosis of these syndromes that consists of the following steps: 1) methylation analysis, which does not require parental samples; 2) microsatellite genotyping of patient and parents to differentiate deletions, UPD and imprinting mutations; and 3) FISH for otherwise uninformative cases, and whenever parental samples are not available. Of the 34 patients whose PWS or AS diagnoses were not confirmed by laboratory tests, five presented a small extra marker chromosome, identified in three of them as an inv dup(15). One AS patient carried a balanced $t(15 ; 15)$ translocation associated with paternal UPD. Therefore G-banded chromosome analysis should be performed on all such patients, to detect possible structural rearrangements.
\end{abstract}

Key words: Angelman syndrome, Prader-Willi syndrome, diagnosis, 15q deletion, uniparental disomy, genomic imprinting.

Received: March 5, 2002; accepted: March 25, 2002.

\section{Introduction}

The Prader-Willi (PWS) and Angelman (AS) syndromes are clinically distinct developmental and neuro-behavioral disorders resulting from the loss of imprinted gene expression within chromosome 15q11-q13 (Nicholls et al., 1998; Nicholls and Knepper, 2001). PWS patients show neonatal hypotonia, with poor sucking and failure to thrive, hyperphagia with onset at 1-6 years of age, severe obesity, mild mental retardation, hypogonadism and characteristic facies and behavior (Prader et al., 1956; Holm et al., 1993; Cassidy, 1997, Fridman et al., 2000a). AS patients present delayed psychomotor development, severe mental retardation, absence of speech, typical happy disposition with outbursts of laughter, ataxia, seizures, microcephaly, macrostomia, and prognathism (Angelman, 1965; Williams et al., 1995, Fridman et al., 2000b, Lossie et al., 2001). The prevalence of these syndromes has been reported to be 1/15-20,000 for PWS (Cassidy, 1997) and 1/20,000 for AS (Clayton-Smith, 1993).

Send correspondence to M.C. Varela, Departamento de Biologia, Instituto de Biociências, USP, C.P. 11.461,05422-970 São Paulo, SP, Brasil. E-mail: mcvarela@ib.usp.br.
PWS and AS are clear examples of genomic imprinting in humans since, the clinical manifestations of these syndromes depend on the parental origin of the mutations within the $15 \mathrm{q} 11$-q13 segment. Approximately $70-75 \%$ of individuals with PWS and AS have 15q11-q13 deletions, which are of paternal origin in PWS and of maternal origin in AS (Knoll et al., 1989; Magenis et al., 1990). Maternal uniparental disomy (UPD) of chromosome 15 is found in about $25 \%$ of PWS patients (Mascari et al., 1992), whereas paternal UPD occurs in only $2-3 \%$ of patients with AS (Magenis et al., 1990). About 1-5\% of patients with PWS and AS have biparental inheritance of chromosome 15, but show abnormal methylation pattern and gene expression due to mutations in the imprinting center (Buiting et al., 1995; Saitoh et al., 1996; Ohta et al., 1999). Some AS patients $(\sim 8 \%)$ may also have mutations in the UBE3A gene (Kishino et al., 1997; Matsuura et al., 1997; Malzac et al., 1998).

The recurrence risk in deletion and UPD cases is less than $1 \%$, whereas for familial imprinting mutation and UBE3A mutation the risk can be as high as 50\% (Bürger et al., 1997; Saitoh et al., 1997). Therefore, the identification of the genetic mechanism involved in each patient is a 
requisite for genetic counseling and depends on the efficiency and reliability of genetic tests.

We report here on 72 patients with a clinical diagnosis of PWS or AS, who underwent chromosome analysis, SNRPN-SNURF exon 1 methylation assay and microsatellite genotyping. A strategy for the diagnosis of these syndromes is proposed.

\section{Material and Methods}

\section{Patients}

Genetic studies were carried out on 72 patients with a clinical diagnosis of PWS (28 patients, 12 males and 16 females) and AS (44 patients, 19 males and 25 females). These patients were referred for genetic tests by the Departments of Neurology, Endocrinology and The Children's Institute, Hospital das Clínicas of the University of São Paulo, from December 1996 to December 1998 (Varela, 1999; 2000).

Most of these patients were examined by at least one of the authors, but in some cases only blood samples were provided, with a brief clinical description. The clinical diagnosis of PWS was based on the presence of mild to moderate mental retardation, obesity and hyperphagia in adolescents, and hypotonia, poor sucking and hypogonadism in infants and children. For AS patients, the diagnostic features were delayed psychomotor development, severe mental retardation, absence of speech, typical happy disposition with outbursts of laughter, and ataxia. Ages ranged from 9 months to 18 years in PWS patients, and from 17 months to 11 years in AS patients.

\section{Cytogenetic studies}

Chromosome studies of patients and their parents were performed on peripheral blood lymphocytes, after GTG-banding. FISH was performed with the SNRPN and GABRB3 probes (ONCOR, Gaithersburg, MD). For the identification of extra marker chromosomes, a chromosome $15 \alpha$-satellite probe (D15Z; ONCOR, Gaithersburg, MD) was used. In situ hybridization and immunochemical detection were carried out according to the manufacturer's instructions. At least 20 metaphases were analyzed per case.

\section{Methylation analysis}

DNA was extracted from peripheral blood leukocytes by standard procedures. The methylation status of the PWS/AS region was assessed by Southern blotting. Genomic DNA double digested with $X b a \mathrm{I}$ and NotI was separated by electrophoresis on a $1.0 \%$ agarose gel, and transferred to a nylon membrane. $\mathrm{A}^{32} \mathrm{P}$ labeled $0.6 \mathrm{~kb}$ EcoRI-Not fragment, which contains exon 1 of $S N R P N-S N U R F$, was used as a probe (Glenn et al., 1996). In this assay, PWS patients present a single $4.2 \mathrm{~kb}$ methylated maternal band, whereas AS patients have a $0.9 \mathrm{~kb}$ non-methylated paternal band. Normal individuals have both bands.

\section{Dinucleotide repeat $(C A)_{n}$ polymorphisms}

Microsatellite analysis was performed using three markers within the critical region 15q11-q13 [4-3RCA (D15S11), LS6-1CA (D15S113) and GABRB3RCA (GABRB3)], after multiplex PCR and polyacrylamide gel eletrophoresis (Mutirangura et al. 1993). The genotyping of two loci outside the PWS/AS region (D15S117 and D15S984) allowed to distinguish a deletion from a UPD: uniparental inheritance within the PWS/AS region together with biparental inheritance outside this region identifies a deletion; the presence of uniparental inheritance both within and outside the critical region reveals a UPD.

\section{Results}

The methylation pattern analysis confirmed the diagnosis of PWS syndrome in 18 out of 28 patients, and of AS syndrome in 20 out of 44 patients (Figure 1). The results are summarized in Figure 2.

The patients with a typical PWS or AS methylation pattern $(\mathrm{n}=38)$ had their chromosomes analyzed after high resolution banding (GTG). The 15q11-q13 microdeletion was detected in seven (20\%) patients (4 PWS and $3 \mathrm{AS}$ ); in five (14.28\%) patients (3 PWS and $2 \mathrm{AS}$ ) the presence of a microdeletion was incertain; 22 patients $(62.8 \%)$ had normal karyotypes (10 PWS and 12 AS), and in one (2.8\%), a Robertsonian translocation [t(15;15)] was identified. All parents had normal karyotypes.

After in situ hybridization, deletions were detected in 14 PWS patients (77.8\%; four of them previously detected by GTG banding) and in 16 AS patients $(80 \%$; three of

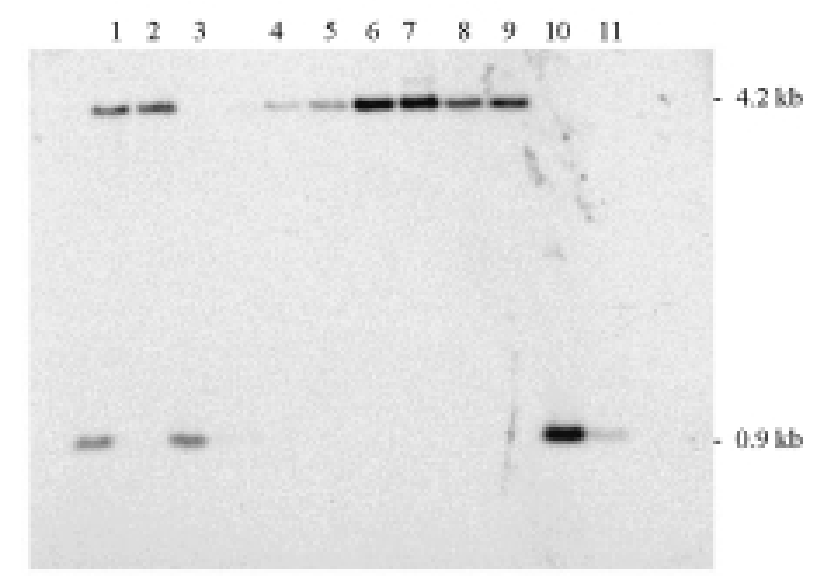

Figure 1 - Southern blotting methylation assay for PWS/AS. Lane 1: normal control; lane 2: PWS control; lane 3: AS control; lanes 4-9: PWS patients; lanes 10-11: AS patients. 
A.

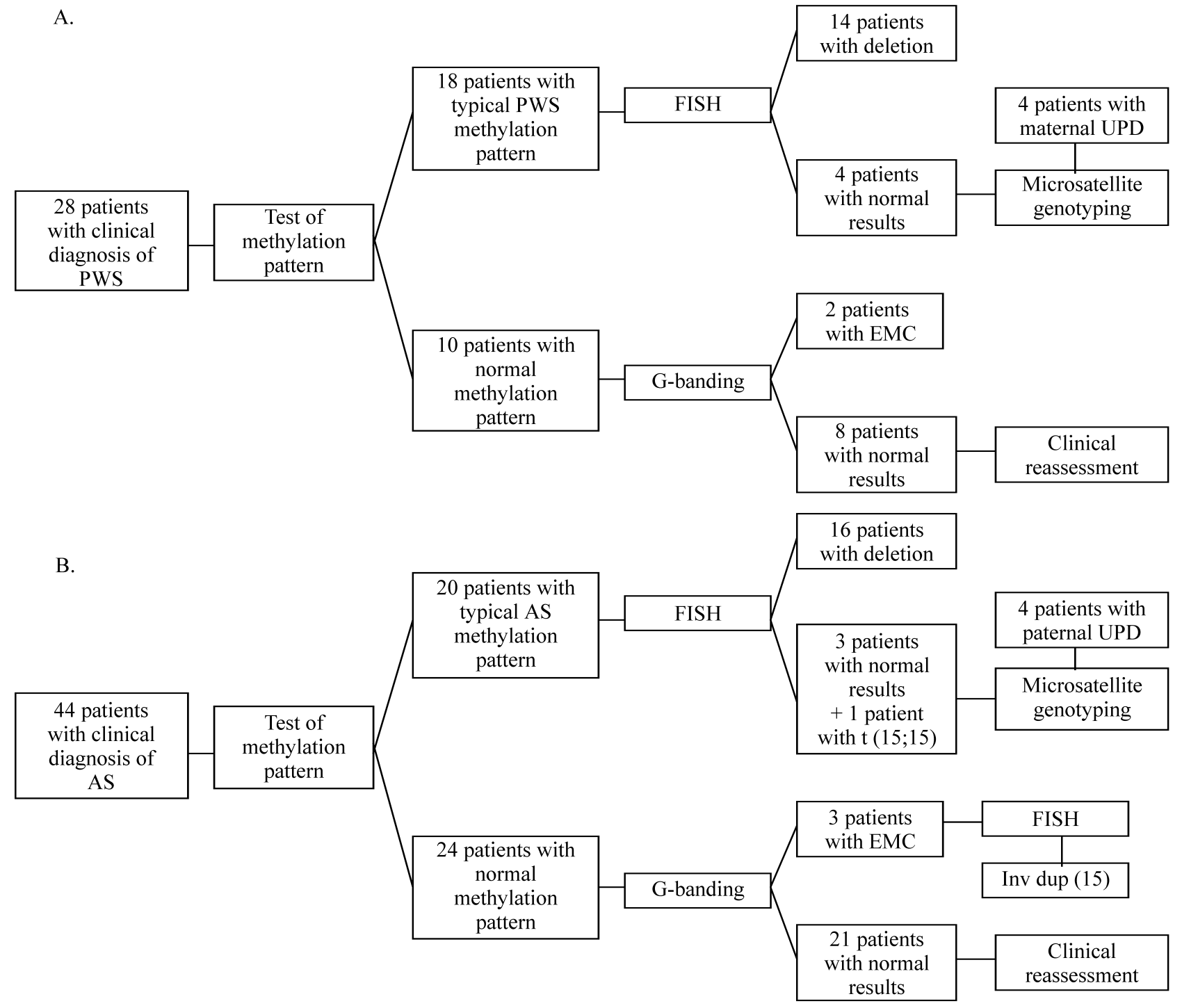

Figure 2 - A summary of the cytogenetic and molecular findings of 28 patients with clinical diagnosis of PWS (A) and 44 patients with clinical diagnosis of AS (B).

them detected previously by GTG banding) (Figure 3a). In the As patient with the $\mathrm{t}(15 ; 15)$ translocation, no deletion was apparent. No abnormalities were observed in the seven remaining cases, who also presented normal karyotypes on GTG-banding analysis.

Microsatellite genotyping was performed in 33 of the 38 patients with a typical methylation pattern, since parental samples were not available for the other five cases. A deletion was detected in $20(60.6 \%)$ patients (7 with PWS and 13 with AS). Eight (24.3\%) patients had UPD (Figure 4), including seven patients with normal FISH results and the AS patient with the $t(15 ; 15)$. In five cases $(15.1 \%)$ the results were uninformative.

Among the 34 patients with normal methylation patterns, chromosome analysis after GTG banding revealed five cases (2 "PWS patients" and 3 "AS patients") with an extra marker chromosome (EMC) with the size of a
G-group chromosome. In the two "PWS patients", the EMC did not show FISH signals of the $\alpha$-satellite D15Z probe nor of the single-copy sequences GABRB3 and SNRPN. Two FISH signals were observed on the EMCs in the three "AS patients", allowing these markers to be identified as inv dup (15) (Figure 3b). The clinical description of these three patients can be found in Varela et al. (1999). Microsatellite genotyping with markers within the PWS/AS critical region was performed on these inv dup(15) carriers. The presence of three alleles (two maternal and one paternal) of the marker GABRB3 confirmed that the FISH signals observed on the EMCs were produced by probe GABRB3 and not by the control probe. The maternal origin of the markers was established. All of the 29 remaining cases with normal methylation patterns presented normal karyotypes. 

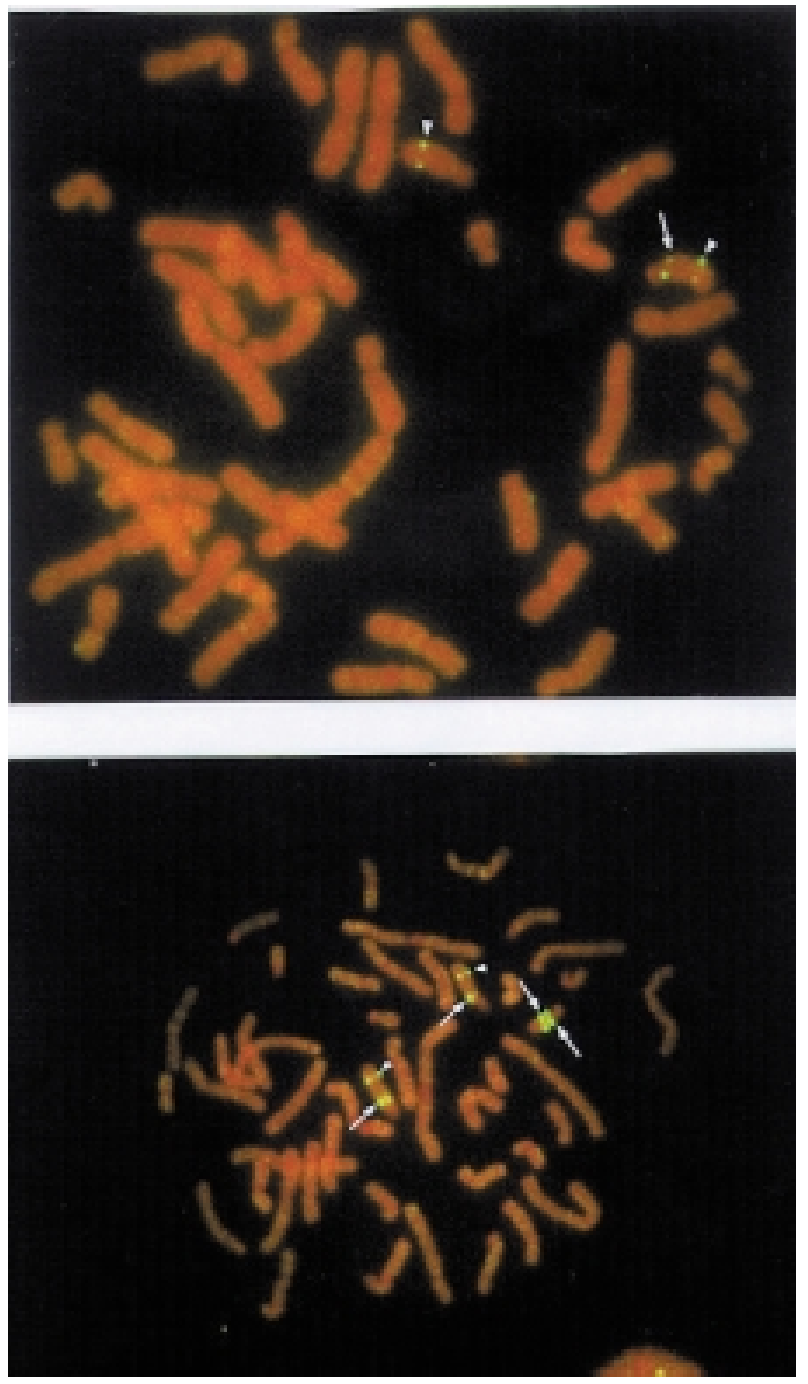

Figure 3 - FISH with GABRB3 probe (arrows) shows (a) a deletion and (b) a duplication in an inv dup (15). The signal of a control probe located at $15 \mathrm{q} 22$ is seen (arrowheads).

\section{Discussion}

This work is part of an ongoing research on children with PWS and AS. The diagnostic hypothesis of PWS or AS was initially investigated by SNRPN-SNURF methylation analysis. This test has been used as a diagnostic tool for PWS and AS, since the methylation pattern is parent-specific in this region (Glenn et al., 1996; Kubota et al., 1996) and detects patients with deletion, UPD and imprinting mutations, which account for $99 \%$ of PWS and $85 \%$ of AS cases.

Classical cytogenetic techniques have low sensitivity for the detection of microdeletions, even at higher banding levels. Differences in condensation of band 15q12 in homologues make it difficult to detect a deletion in this region: in our study, only seven of the 30 patients $(23.3 \%)$ with a deletion were detected by this method. FISH with chromosome 15q11-q13 probes was the most efficient cytogenetic

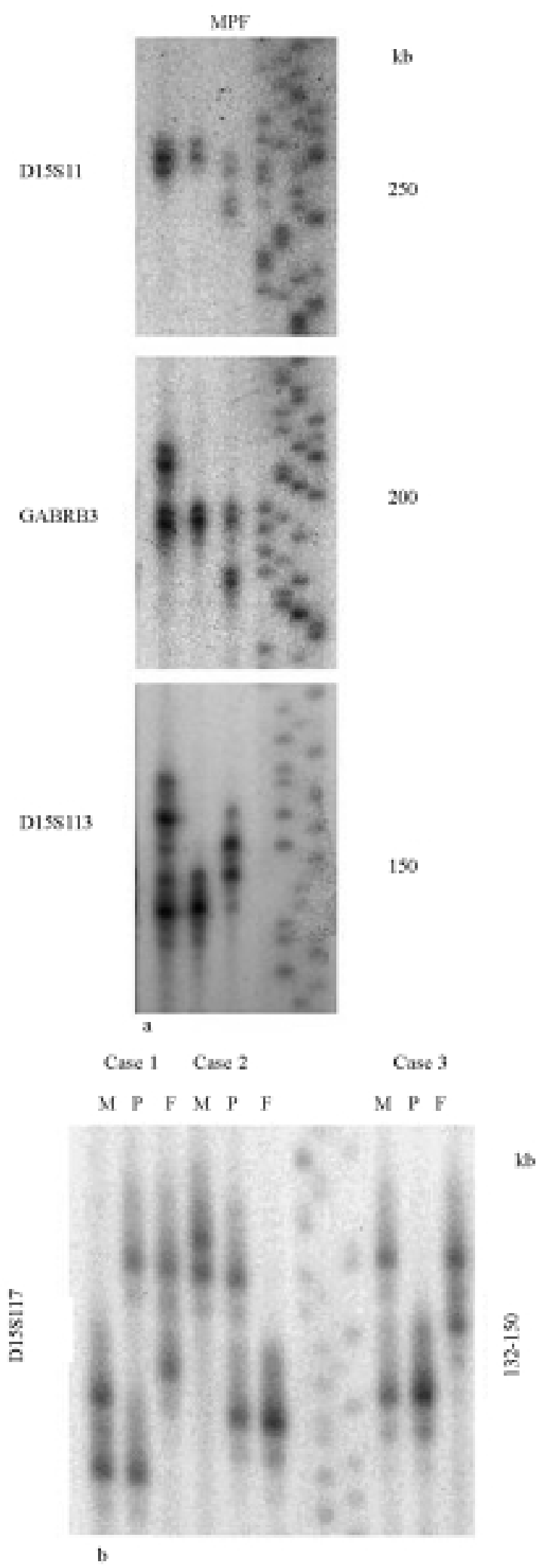

Figure 4 - Microsatellite genotyping: a) multiplex PCR of loci D15S11, GABRB3 and D15S113; only the maternal allele is present in the patient; b) PCR of locus D15S117 mapped outside the PWS/AS region, in cases with only maternally inherited alleles mapped to 15q11-q13; cases 1 and 2 show biparental inheritance, indicating a deletion; case 3 inherited only the maternal allele, indicating a maternal UPD. $\mathrm{M}=$ mother, $\mathrm{P}=$ patient, and $\mathrm{F}=$ father. $\mathrm{M} 13 \mathrm{mp} 18$ sequencing standard was used for allele sizing. 
diagnostic test for PWS and AS, identifying a deletion in about $79 \%(30 / 38)$ of the patients.

Since FISH does not detect UPD, imprinting or UBE3A mutations, the remaining patients require DNA analysis using microsatellite markers within and outside the PWS/AS region. Eight patients with UPD (four PWS and four AS) were detected in this sample. The disadvantage of this methodology is that it requires parental blood samples and, even when they are available, the results can be uninformative (as in $15.1 \%$ of our sample).

So, an efficient strategy for the routine diagnosis of PWS and AS patients (Figure 2) consists of: a) methylation analysis, that allows the diagnosis of $99 \%$ of PWS and $85 \%$ of AS patients, and does not require parental samples; $b$ ) microsatellite genotyping of the family (child, mother and father) to diagnose deletions, UPD or imprinting mutations; c) in uninformative cases or if parental samples are not available, the FISH technique is recommended, since it appears to detect all the deletions ( $\sim 75 \%$ of PWS and AS patients). Routine cytogenetic studies after G-banding should be performed in all patients referred with a clinical diagnosis of PWS or AS. Among the 20 patients whose diagnosis of AS was confirmed, one carried a balanced $\mathrm{t}(15 ; 15)$. Indeed, about $5 \%$ of PWS and AS of the literature present a chromosome rearrangement (Butler, 1990).

Patients with hypotonia, delayed psychomotor development, severe mental retardation, seizures and dysmorphic features, frequently referred as "suspected AS", may be carriers of an extra marker derived from chromosome 15 [inv dup(15)]. In the present sample, three such carriers were found, and the incidence of this marker appears to be as high as 1/5,000 births (Buckton et al., 1995). FISH using repetitive, single-copy, or whole-chromosome painting probes is a requisite for the proper identification of these extra chromosomes. Microsatellite genotyping is useful to disclose their parental origin, also allowing to better characterize their genetic content. The phenotypic variability observed among patients with inv dup(15) is influenced by the origin of the marker, by the extent of the euchromatic segment and by its isodysomic or heterodysomic nature (Mignon et al., 1996).

In patients with a normal methylation pattern and normal chromosomes, a clinical reassessment is recommended to determine whether additional DNA investigations are indicated. Among "AS patients" with a normal methylation pattern, cases can be found who carry a UBE3A mutation that accounts for approximately $8 \%$ of patients with the clinical features of AS (Nicholls et al., 1998).

\section{Acknowledgments}

This work was supported by FAPESP (M.C.V. 97/02383-0, C.F. 95/07161-0), CNPq and PRONEX. Dr Robert D. Nicholls kindly provided the SNRPN-SNURF exon 1 probe. We thank Ms. Roseli M. Zanelato for technical assistance.

\section{References}

Angelman H (1965) "Puppet" children: a report on three cases. Develop Med Child Neurol 7:681-688.

Buiting K, Saitoh S, Gross S, Dittrich B, Schwartz S, Nicholls RD and Horsthemke B (1995) Inherited microdeletions in the Angelman and Prader-Willi syndromes define an imprinting center on human chromosome 15. Nature Genet 9:395-400.

Buckton KE, Spowart G, Newton MS and Evans JH (1985) Forty-four probands with an additional "marker" chromosome. Hum Genet 69:353-370.

Bürger J, Buiting K, Dittrich B, Gro S, Lich C, Sperling K, Horsthemke B and Reis A (1997) Different mechanisms and recurrence risks of imprinting defects in Angelman syndrome. Am J Hum Genet 61:88-93.

Butler MG (1990) Prader-Willi syndrome: current understanding of cause and diagnosis. Am J Hum Genet 35:319-332.

Cassidy SB (1997) Prader-Willi syndrome. J Med Genet 34:917-923.

Clayton-Smith J (1993) Clinical research on Angelman syndrome in the United Kingdom: observations on 82 affected individuals. Am J Med Genet. 46:12-15.

de Vries BB, Fryns JP, Butler MG, Canziani F, Wesby-van SE, van Hemel JO, Oostra BA, Halley DJ and Niermeijer MF (1993) Clinical and molecular studies in fragile X patients with a Prader-Willi-like phenotype. J Med Genet 30:761-766.

Eugster EA, Berry SA and Hirsch B (1997) Mosaicism for deletion $1 \mathrm{p} 36.33$ in a patient with obesity and hyperphagia. Am J Med Genet 70:409-412.

Fridman C, Varela MC, Kok F, Setian N and Koiffmann CP (2000a) Prader-Willi syndrome: genetic tests and clinical findings. Genetic Testing 4:387-392.

Fridman C, Varela MC, Kok F, Diament A and Koiffmann CP (2000b) Paternal UPD15: further genetic and clinical studies in four Angelman syndrome patients. Am J Med Genet 92:322-327.

Glenn CC, Saitoh S, Jong MTC, Filbrandt MM, Surti U, Driscoll DJ and Nicholls RD (1996) Gene structure, DNA methylation, and imprinted expression of the human SNRPN gene. Am J Hum Genet 58:335-346.

Holm VA, Cassidy SB, Butler MG, Hanchett JM, Greenswag LR, Whitman BY and Greenberg F (1993) Prader-Willi syndrome: consensus diagnostic criteria. Pediatrics 91:398-402.

Kishino T, Lalande M and Wagstaff J (1997) UBE3A/E6AP mutations cause Angelman syndrome. Nature Genet 15:70-73.

Knoll JHM, Nicholls RD, Magenis RE, Graham Jr JM, Lalande M and Latt SA (1989) Angelman and Prader-Willi syndromes share a common chromosome 15 deletion but differ in parental origin of the deletion. Am J Med Genet 32:285-290.

Kubota T, Sutcliffe JS, Aradhya S, Gillessen-Kaesbach G, Christian SL, Horsthemke B, Beaudet AL and Ledbetter DH (1996) Validation studies of SNRPN methylation as a diagnostic test for Prader-Willi syndrome. Am J Med Genet 66:77-80.

Lossie AC, Whitney MM, Amidon D, Dong HJ, Chen P, Theriaque D, Hutson A, Nicholls RD, Zori RT, Williams CA and Driscoll DJ (2001) Distinct phenotypes distinguish the molecular classes of Angelman syndromes. J Hum Genet 38:834-845.

Malzac P, Webber H, Moncla A, Graham Jr JM, Kukolich M, Williams C, Pagon RA, Ramsdell LA, Kishino T and Wag- 
staff J (1998) Mutation Analysis of UBE3A in Angelman syndrome patients. Am J Hum Genet 32:1353-1360.

Magenis RE, Toth-Fejel S, Allen LJ, Black M, Brown MG, Budden S, Cohen R, Friedman JM, Kalousek D, Zonana J, Lacy D, LaFranchi S, Lahr M, Macfarlane J and Williams CPS (1990) Comparison of the $15 \mathrm{q}$ deletions in Prader-Willi and Angelman syndromes: specific regions, extent of deletions, parental origin, and clinical consequences. Am J Med Genet 35:333-349.

Mascari MJ, Gottlieb W, Rogan PK, Butler MG, Waller DA, Armour JAL, Jeffreys AJ, Ladda RL and Nicholls RD (1992) The frequency of uniparental disomy in Prader-Willi syndrome. N Engl J Med 326:1599-607.

Matsuura T, Sutcliffe JS, Fang P, Galjaard R-J, Jiang Y-H, Benton CS, Rommens JM and Beaudet AL (1997) De novo truncating mutations in E6-AP ubiquitin-protein ligase gene (UBE3A) in Angelman syndrome. Nature Genet 15:74-77.

Mignon C, Malzac P, Moncla A, Depetris D, Roeckel N, Croquette M-F and Mattei M-G (1996) Clinical heterogeneity in 16 patients with inv dup 15 chromosome: cytogenetic and molecular studies, search for imprinting effect. Euro J Hum Genet 4:88-100.

Mutirangura A, Jayakumar A, Sutcliffe JS, Nakao M, McKinney MJ, Buiting K, Horsthemke B, Beaudet A, Chinault AC and Ledbetter DH (1993) A complete YAC contig of the Prader-Willi/Angelman chromosome region (15q11-q13) and refined localization of the SNRPN gene. Genomics 18:546-552.

Nicholls RD and Knepper JL (2001) Genome organization, function, and imprinting in Prader-Willi and Angelman syndromes. Annu Ver Genomics Hum Genet 2:153-175.

Nicholls RD, Saitoh S and Horsthemke B (1998) Imprinting in Prader-Willi and Angelman syndromes. TIG 14:194-200.

Ohta T, Buiting K, Kokkonen H, Mc Candless S, Heeger S, Leisti H, Driscoll DJ, Cassidy SB, Horsthemke B and Nicholls RD (1999) Molecular mechanism of Angelman syndrome in two large families involves an imprinting mutation. Am J Hum Genet 64:385-396.
Prader A, Labhart A and Willi H (1956) Ein Syndrom von Adipositas, Kleinwuchs, Kryptorchismus und Oligophrenie nach myotonieartigem Zustand im Neugeborenenalter. Schweiz Med Wochenschr 86:1260-1261.

Saitoh S, Buiting K, Cassidy SB, Conroy JM, Driscoll DJ, Gabriel JM, Gillessen-Kaesbach G, Glenn CC, Greenswag LR, Horsthemke B, Kondo I, Kuwajima K, Niikawa N, Rogan PK, Schwartz S, Seip J, Williams CA and Nicholls RD (1997) Clinical spectrum and molecular diagnosis of Angelman and Prader-Willi syndrome imprinting mutation patients. Am J Med Genet 68:195-206.

Saitoh S, Buiting K, Rogan PK, Buxton JL, Driscoll DJ, Arnemann J, Konig R, Malcolm S, Horsthemke B and Nicholls RD (1996) Minimal definition of the imprinting center and fixation of a chromosome 15q11-q13 epigenotype by imprinting mutations. Proc Natl Acad Sci USA 93:7811-7815.

Stein CK, Stred SE, Thomson LL, Smith FC and Hoo JJ (1996) Intersticial 6q deletion and Prader-Willi-like phenotype. Clin Genet 49:306-310.

Varela MC (1999) Síndromes de Prader-Willi e Angelman: Análise Cromossômica, Espectro da Variabilidade Fenotípica e o Papel dos Cromossomos Marcadores. Master's Thesis. Instituto de Biociências, Universidade de São Paulo, São Paulo, Brasil.

Varela MC (2000) Prader-Willi and Angelman syndromes: chromosome analysis, the spectrum of the clinical variability and the study of marker chromosomes. Master's Thesis Abstract. Genet Mol Biol 23 (1):249-250.

Varela MC, Fridman C, Matsumoto TE, Kim CA, Kok F, Diament A and Koiffmann CP (1999) A clinical, cytogenetic and molecular study of three Brazilian patients with supernumerary inv dup(15) marker chromosomes. Am J Hum Genet 65 [suppl]:A347 (\#1962).

Williams CA, Angelman H, Clayton-Smith J, Driscoll DJ, Hendrickson JE, Knoll JHM, Magenis RE, Schinzel A, Wagstaff J, Whidden EM and Zori RT (1995) Angelman syndrome: consensus for diagnostic criteria. Am J Med Genet 56:237-238. 